\title{
Description of Evandromyia (Aldamyia) orcyi, a new phlebotomine species (Diptera: Psychodidae: Phlebotominae) from the State of Mato Grosso do Sul, Brazil
}

\author{
Alessandra Gutierrez de Oliveira ${ }^{1}$, Cristiani de Castilho Sanguinette ${ }^{2}$, Paulo Silva de Almeida ${ }^{3}$ \\ and José Dilermando Andrade Filho ${ }^{2^{*}}$
}

\begin{abstract}
Background: The genus Evandromyia is widely found in Brazil, but occurs mainly in Brazilian savannah. To date 13 species have been described in the subgenus Aldamyia. Here we described a new species of Evandromyia (Aldamyia) collected in the State of Mato Grosso do Sul, Brazil.

Methods: Measurements were made using a micrometer eyepiece on an Olympus $\mathrm{CH}-2$ binocular microscope and drawings were executed with the aid of a camera lucida.

Results: The new species, Evandromyia orcyi sp. nov., is closely related to Evandromyia lenti, Evandromyia carmelinoi and Evandromyia evandroi, however, characteristics of the male terminalia and female spermathecae distinguish it from other species of the genus Evandromyia.

Conclusion: With the description of Evandromyia orcyi sp. nov., six species of the subgenus Aldamyia have been reported from the State of Mato Grosso do Sul.
\end{abstract}

Keywords: Evandromyia orsyi sp. nov, Sand fly, Mato Grosso do Sul, Leishmaniasis

\section{Background}

Insects of the subfamily Phlebotominae are the natural vectors of Leishmania throughout the world. In Brazil, about 270 species belonging to 19 genera have been reported [1], but the number of described species has been increasing [2,3]. Evandromyia is a genus widely found in Brazil, but occurs mainly in areas covered by savannah [4,5]. According to Galati [6], this genus is divided in three subgenera: Aldamyia, Evandromyia and Barrettomyia. To date, Aldamyia contains 13 species, five of which occur in the State of Mato Grosso do Sul [6-8].

Males of Aldamyia are characterized by the absence of papillae on tergite VII and their presence on tergite VI, terminalia with the gonostyle bearing four spines, gonocoxite

\footnotetext{
* Correspondence: jandrade@cpqrr.fiocruz.br

${ }^{2}$ Grupo de Estudos em Leishmanioses, Coleção de Flebotomíneos, Centro de Referência Nacional e Internacional para Flebotomíneos, Instituto René Rachou, Fiocruz, Av. Augusto de Lima 1715, 30190-002 Belo Horizonte, MG, Brazil

Full list of author information is available at the end of the article
}

with a tuft of setae, and, in females a generally appleshaped spermathecae and cibarium with the anterior teeth in lateral sets [6].

During entomological surveillance carried out by a vector control team, a new species of sand fly was found. This study describes both sexes of this new species of sand fly belonging to the genus Evandromyia.

\section{Methods}

Sand flies were collected using CDC light traps in the District of Vestia, Selvíria County, State of Mato Grosso do Sul, Brazil $\left(20^{\circ} 22^{\prime} 11^{\prime \prime} \mathrm{S}\right.$ and $\left.51^{\circ} 25^{\prime} 09^{\prime \prime} \mathrm{W}\right)$ in April 2009. Authorization to collect zoological material was granted by the Brazilian Institute of Environment and Renewable Natural Resources - IBAMA (SISBio 25952-1). Sand flies were mounted in Canada balsam. Measurements were made using an Olympus $\mathrm{CH}-2$ binocular microscope with a micrometer eyepiece and drawings were executed with the aid of a camera lucida. Measurements are given 


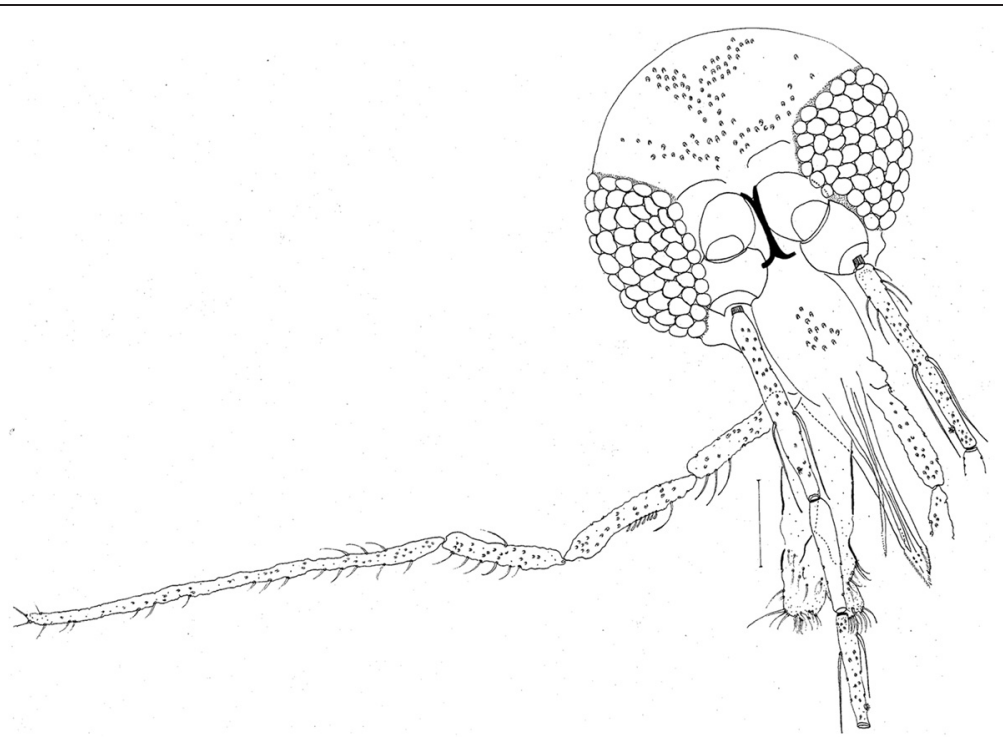

Figure 1 Evandromyia (Aldamyia) orcyi sp. nov. Holotype male: head, frontal view; (Bar = 50 um).

in micrometers and the classification followed is that proposed by Galati [6].

In accordance with section 8.5 of the International Code of Zoological Nomenclature, details of the new species have been submitted to ZooBank with the life science identifier (LSID) http://zoobank.org/References/ ED63311B-899E-4B76-B49C-88C004862D24.

The following description of Evandromyia (Aldamyia) orcyi sp. nov., is based on three male specimens and one female specimen. Measurements of the male holotype are given with, in brackets, the mean, standard deviation and number of male paratypes examined for each structure.

\section{Description}

Evandromyia (Aldamyia) orcyi sp. nov. Oliveira, Sanguinette, Almeida \& Andrade Filho (Figures 1, 2, $3,4,5,6,7,8,9,10,11$ and 12).

\section{Holotype (male)}

Sand fly of small size, measurement ca. 2,633 (2,821 \pm $190.2 ; n=2$ ) in length, general colour light brown.

\section{Head}

Measurement $386(386 \pm 19.8 ; \mathrm{n}=2)$ long and $336(293 \pm$ 29.7; $\mathrm{n}=2$ ) wide (Figure 1). Head length/head width ratio 1.15: $1(1.32 \pm 0.07 ; \mathrm{n}=2)$. Clypeus $152(151 \pm 12.0 ; \mathrm{n}=2)$ long; clypeus length/head length ratio 0.39: 1 (0.39: $1 \pm$ $0.01 ; \mathrm{n}=2)$. Eye $191(172 \pm 7.8 ; \mathrm{n}=2)$ long and 103 $(99 \pm 9.9 ; \mathrm{n}=2)$ wide; eye length/head length $0.49: 1$ $(0.44: 1 \pm 0.00 ; \mathrm{n}=2)$. Interocular distance $124(122 \pm$ 22.6; $\mathrm{n}=2)$. Labrum-epipharynx (LE) $205(206 \pm 4.9 ; \mathrm{n}=2)$. LE/head length 0.53: $1(0.53 \pm 0.01 ; n=2)$. Antenna with simple and long ascoid, reaching the basis of the next segment. Flagellomere lengths: AIII 212; AIV 113 (127; $\mathrm{n}=1)$; AV $113(131 ; \mathrm{n}=1)$; AXV > AXVI. In the paratypes the flagellomere were lost. Papilla present in AIII, AIV, AV, AXIII-AXVI. Ratios: AIII/head length 0.55: 1; AIII/LE 1.03: 1. Palpomere lengths: P1 35 (39 $\pm 4.9 ; \mathrm{n}=2)$;

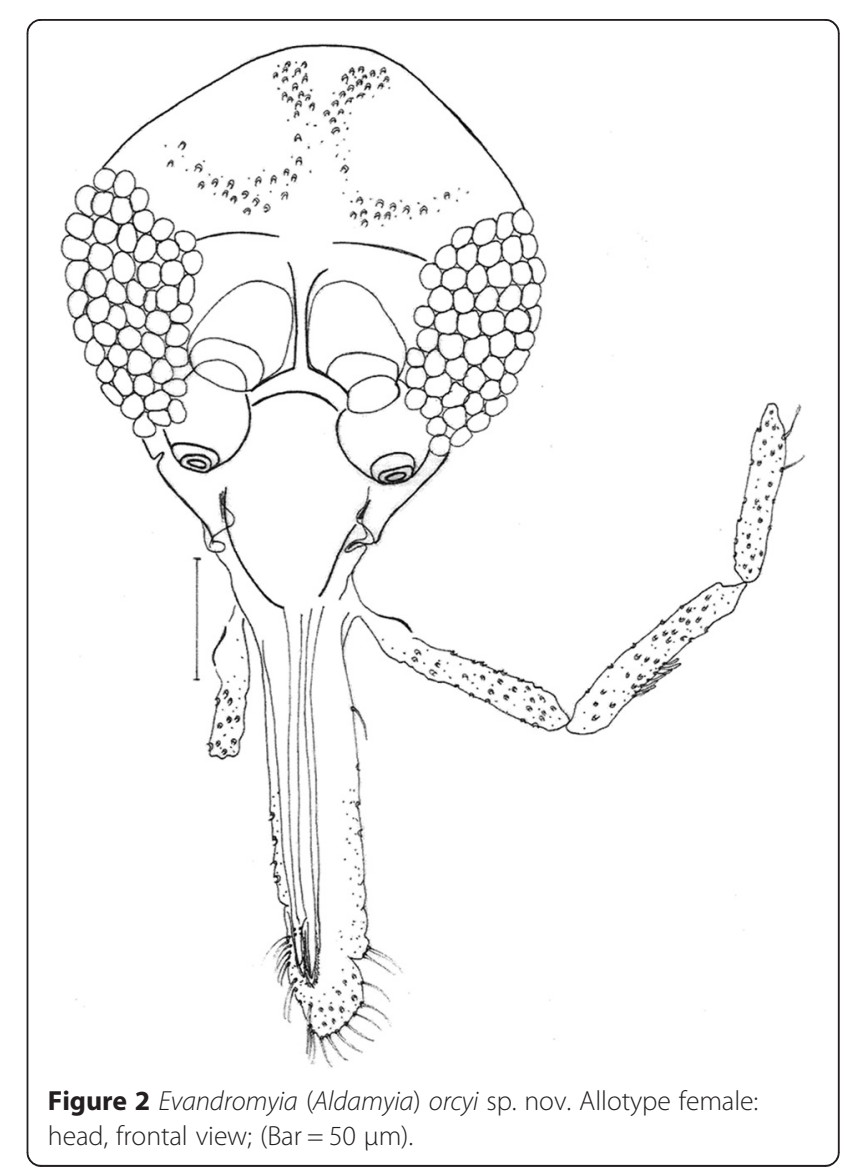




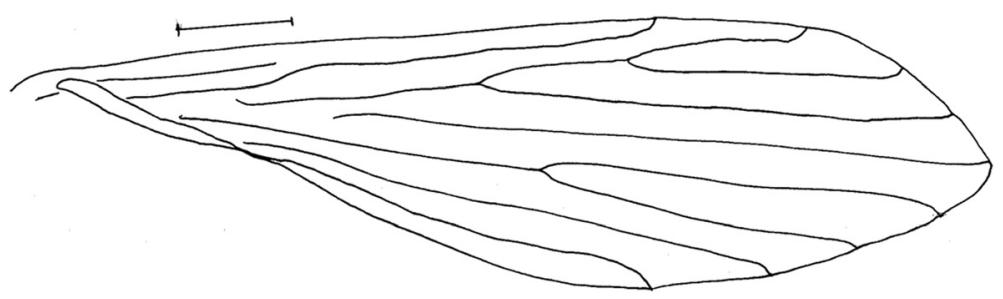

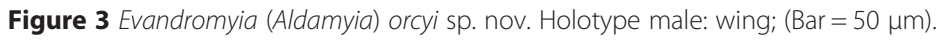

P2 $99(105 \pm 7.8 ; \mathrm{n}=2)$; P3 $149(142 \pm 9.9 ; \mathrm{n}=2) ;$ P4 127 $(115 \pm 12.7 ; \mathrm{n}=2)$; and P5 $340(342 \pm 21.9 ; \mathrm{n}=2)$. Newstead's spines inserted medially on palpomere 3. Labial suture forming a fork.

\section{Ventrocervical sensilla - present Thorax}

Proepimeral setae present, $2-2(2-2 ; \mathrm{n}=2)$ and anepisternal superior setae present, 12-14 (10-10; $\mathrm{n}=1),(10-11$; $\mathrm{n}=1$ ); setae on the anterior region of the katepisternum present. Wing (Figure 3) measurement 1,858 (1,794 \pm 111.0; $\mathrm{n}=2)$ long and $514(501 \pm 40.3 ; \mathrm{n}=2)$ at maximum width. Length/width ratio 3.58: 1 (3.60: $1 \pm 0.07 ; n=2)$. Length of the vein sections: $R_{5} 1,215(1229 \pm 60.8 ; n=2)$; alpha $400(378 \pm 72.1 ; \mathrm{n}=2)$; beta $272(286 \pm 19.8 ; \mathrm{n}=2)$; gamma 286 (293 $\pm 9.9 ; \mathrm{n}=10)$; delta $86(65 \pm 30.4 ; \mathrm{n}=2)$. The legs were lost in all specimens.

\section{Abdomen}

Papillae present on 5th and 6th tergites. Gonostyle 166 $(172 \pm 2.1 ; \mathrm{n}=2)$ long, with four spines: one apical, one upper external, one lower external and one internal implanted below the lower external. Sub terminal seta present. Gonocoxite $319(327 \pm 18.4 ; \mathrm{n}=2)$ long and 110 (76 $\pm 2.8 ; \mathrm{n}=3$ ) wide, with a tuft containing 12-13 long $(11-12 ; \mathrm{n}=2)$ and four-four smaller setae $(4-4 ; \mathrm{n}=2)$. Paramere straight with dorsal setae inserted in the apical half and ventral process on its basal third (see Figure 5). The paramere also present a basal bristly lobe at level of aedeagus. Lateral lobe $428(459 \pm 12.0 ; n=2)$ long and $32(28 \pm 0.0 ; n=2)$ wide, without persistent setae at its apex. Lateral lobe/gonocoxite ratio 1.34: 1 (1.41 \pm 0.12 ; $\mathrm{n}=2$ ). Conical and pigmented aedeagus. Genital filament
(Figure 6) $301(288 \pm 2.8 ; \mathrm{n}=2)$ long and genital pump $159(186 \pm 2.8 ; n=2)$. Genital filament/genital pump ratio 1.89: $1(1.55 \pm 0.01 ; \mathrm{n}=2)$. Tip of genital filaments modified, small arrow-shape.

\section{Allotype (female)}

Sand fly of medium size, measuring ca. 2,501 in length. Coloration as in the male.

\section{Head}

Measurement 386 long and 314 wide. Head length/head width ratio 1.23: 1 . Clypeus 152 long; clypeus length/head length ratio 0.39: 1. Eye 188 long and 96 wide; eye length/ head length 0.49. Interocular distance 142. Labrumepipharynx (LE) 255. LE/head length 0.66: 1. Antenna and fifth palpomere lost. Palpomere lengths: P1 35, P2 117, P3 159, P4 124. Probable palpal formula 1.2.4.3.5. The Newstead spines implanted in the fourth apical of the second palpomere and in the median region of the third palpomere. Cibarium with four posterior teeth well developed and individualized, the anterior teeth are numerous and disposed in lateral sets (Figure 7). Sclerotized area is well defined and the sclerotized arch is complete. Unarmed pharynx. Lacinia of the maxilla with single longitudinal row. Labial suture forming a fork.

\section{Ventrocervical sensilla - present \\ Thorax}

Proepimeral setae present, 1-2 and anepisternal superior setae present, 16-16; setae on the anterior region of the katepisternum present. Wing (Figure 4) measurement 1,960 long and 557 at maximum width. Length/width ratio 3.52: 1 . Length of the vein sections: $\mathrm{R}_{5}$ 1,315; alpha

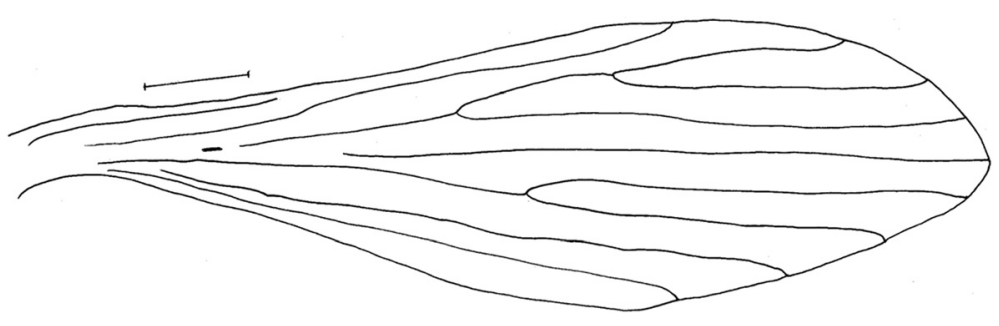

Figure 4 Evandromyia (Aldamyia) orcyi sp. nov. Allotype female: wing, frontal view; (Bar = $50 \mu m)$. 


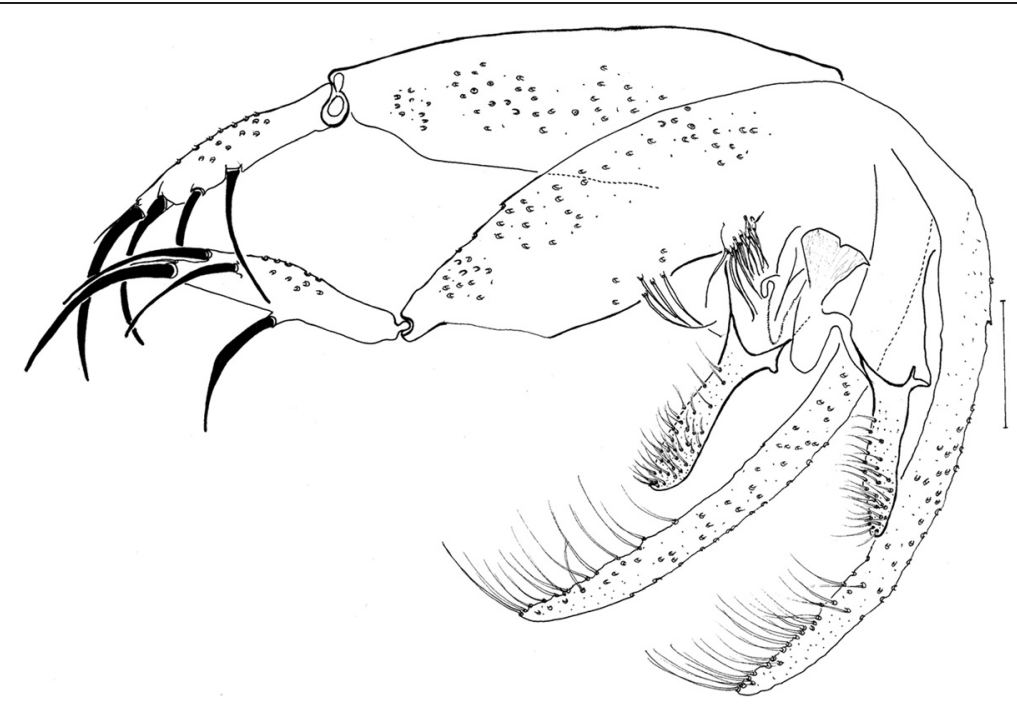

Figure 5 Evandromyia (Aldamyia) orcyi sp. nov. Holotype male: terminalia; (Bar= $100 \mu \mathrm{m})$.

429; beta 314; gamma 272; delta 100. Legs, anterior, median and posterior lost in allotype.

\section{Abdomen}

Spermathecae apple-shaped (Figure 8), 18 long by 18 at maximum width and with distinct terminal knob. The individual duct is 81 in length and the common duct 25 . Individual duct/common duct ratio 3.24: 1. Cercus 177 long.

\section{Type-material}

Holotype, male (N. 90,501), and allotype, female (N. 90,504), collected on 22/IV/2009 using CDC light traps in a hen house at a domestic residence in the District of Vestia, Selvíria County, State of Mato Grosso do Sul, Brazil. Two male paratypes (N. 90,502 and 90,503) were collected with the holotype and allotype. All typematerial is deposited in the "Coleção de Flebotomíneos" of the "Instituto René Rachou/FIOCRUZ" (FIOCRUZCOLFLEB), Belo Horizonte, Brazil.

\section{Etymology}

The name Evandromyia orcyi is given in honor of Mr. Orcy de Oliveira for his great incentive and collaboration in studies with sand flies in the State of Mato Grosso do Sul.

\section{Results and discussion}

The morphological characters of head, thorax and abdomen of the new species place it in the genus Evandromyia, and subgenus Aldamyia. Evandromyia orcyi is most similar to Evandromyia evandroi (Costa Lima \& Antunes, 1936), Evandromyia lenti (Mangabeira, 1938) and Evandromyia carmelinoi (Ryan, Fraiha, Lainson \& Shaw, 1986).

The males of Ev. lenti and Ev. carmelinoi can be distinguished from the new species by characters of their parameres. The new species has a simple paramere with a ventral process on its third basal while the other two species have a bifurcate paramere $[9,10]$. The presence of a basal bristly-lobe at the level of the aedeagus of the paramere can also be used to distinguish Ev. orcyi from all other species of the subgenus except Ev. evandroi [11], which has a similar structure, however, Ev. evandroi does not possess a ventral process on the paramere base. Another character that can be used to distinguish Ev. orcyi from all other species of the subgenus is the unique tip of its genital filament, which is in the form of a small arrow and unlike that of any other species.

Females of the new taxon can be distinguished from Evandromyia aldafalcaoae (Santos, Andrade Filho \& Honer, 2001), Evandromyia apurinan Shimabukuro, Figueira and Silva, 2013, Evandromyia andersoni (Le

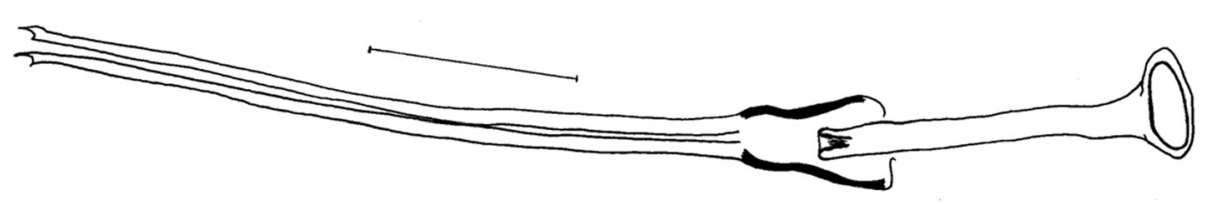

Figure 6 Evandromyia (Aldamyia) orcyi sp. nov. Holotype male: genital pump and filaments; (Bar = $100 \mu \mathrm{m})$. 

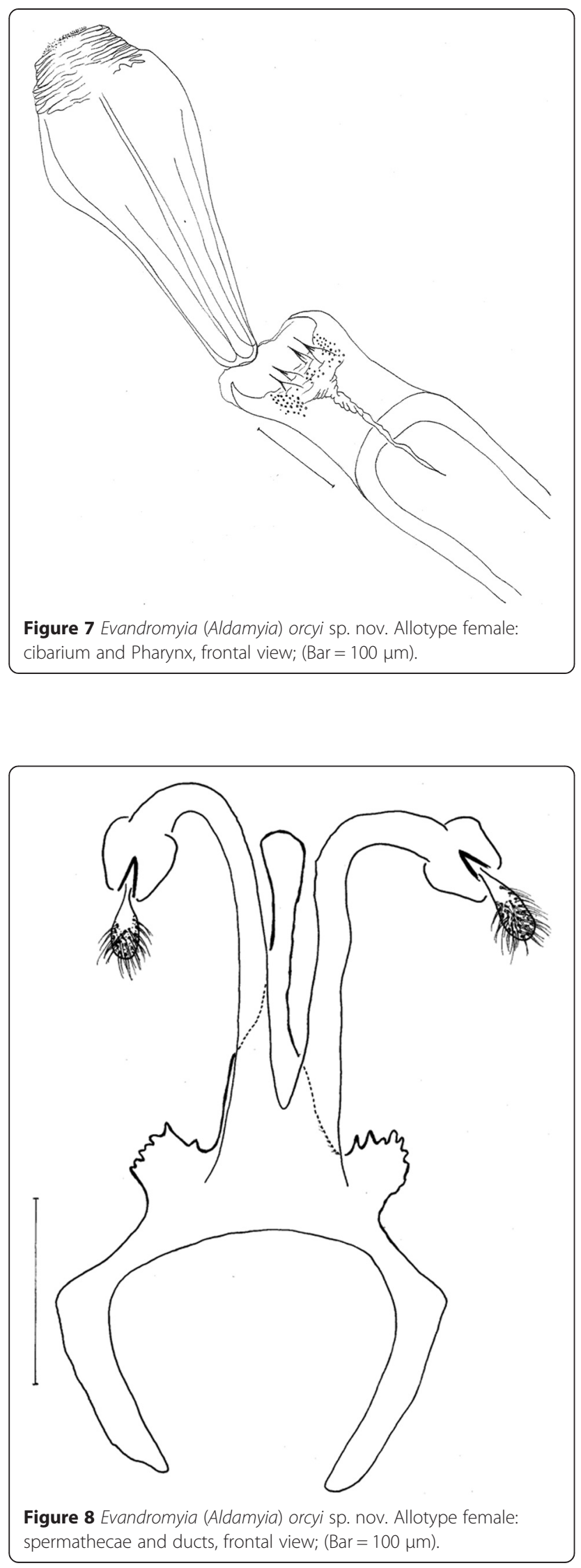

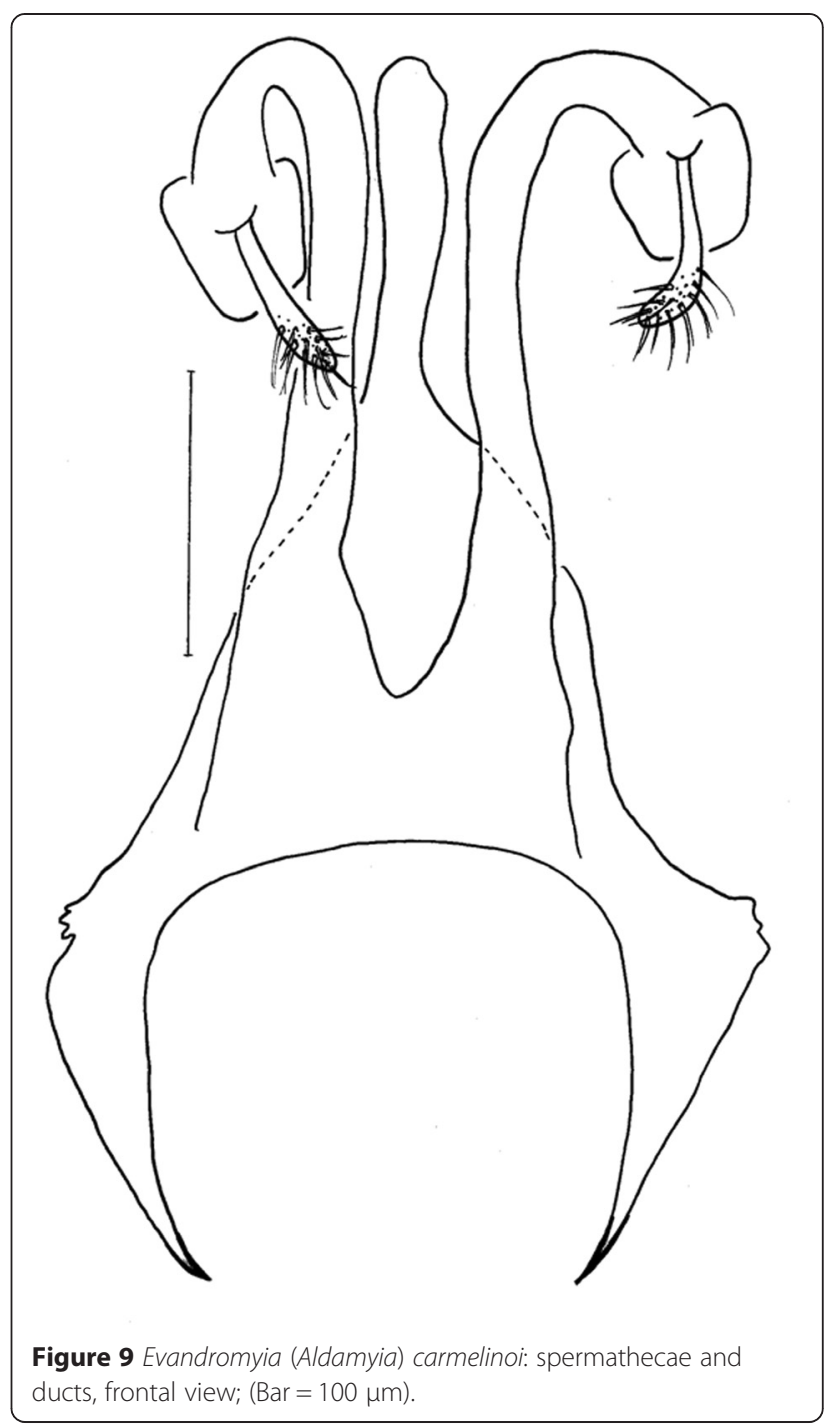

Pont \& Desjeux, 1988), Evandromyia bacula (Martins, Falcão \& Silva, 1965), Evandromyia sericea (Floch \& Abonnenc, 1944), Evandromyia termitophila (Martins, Falcão \& Silva, 1964) and Evandromyia williamsi (Damasceno, Causey \& Arouck, 1945) by the shape of the spermatheca.

Evandromyia evandroi, Ev. lenti, Ev. carmelinoi, Evandromyia dubitans (Sherlock, 1962) and Evandromyia walkeri (Newstead, 1914) have spermathecae that are similar to that of Ev. orcyi, but the latter may be distinguished by the ducts of spermathecae (Figures 9, 10, 11 and 12). The common duct of the spermatheca of $E$. lenti and Ev. carmelinoi have sclerotized external margins, which are absent in the new species. In addition, the common duct of the spermathecae is much larger in these two taxa than in Ev. orcyi. From Ev. walkeri and Ev. dubitans the new species may be differentiated by the length of the common duct, which is subequal to the individual duct in these species and about $1 / 3$ of the 


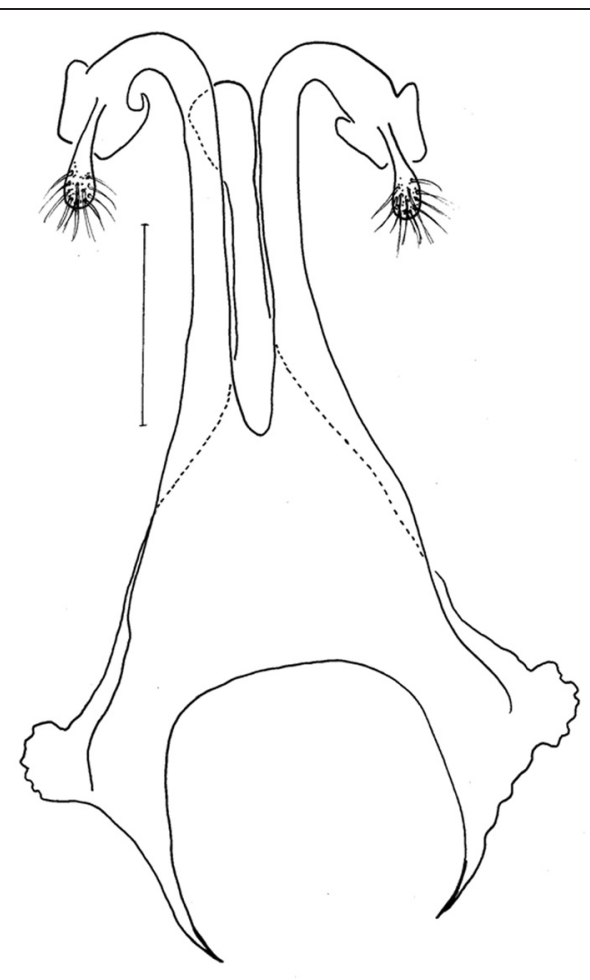

Figure 10 Evandromyia (Aldamyia) lenti: spermathecae and ducts, frontal view; $(\mathrm{Bar}=100 \mu \mathrm{m})$.

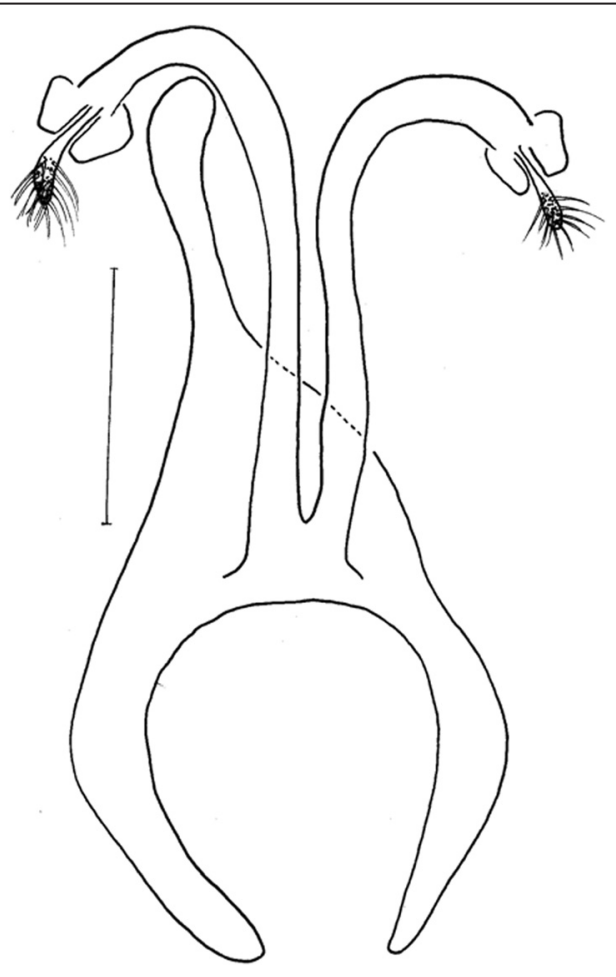

Figure 11 Evandromyia (Aldamyia) evandroi: spermathecae and ducts, frontal view; $(\mathrm{Bar}=100 \mu \mathrm{m})$.

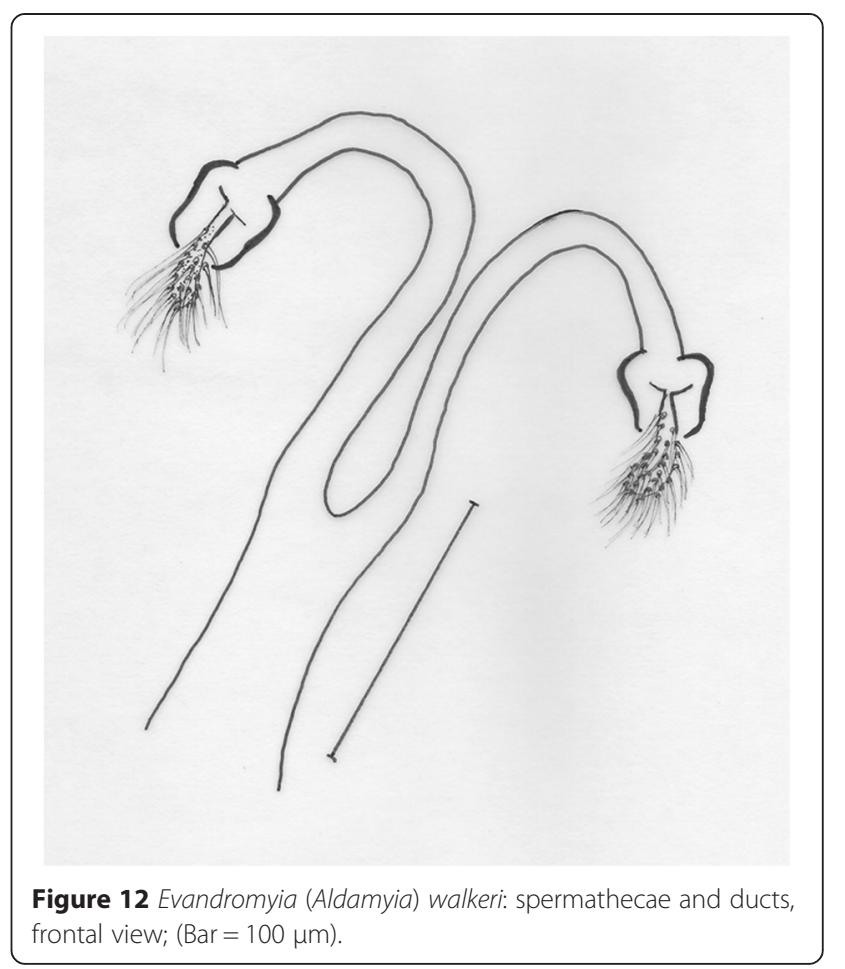

individual duct in Ev. orcyi. Finally, Evandromyia evandroi has the common duct shorter and narrower than the duct of the new species.

The female of Evandromyia hashiguchii Leon, Teran, Neira \& Le Pont, 2009 was not described [12]. The male of this species is morphologically similar to Ev. andersoni and Ev. sericea, which leads us to believe that the female of the new species described here does not correspond to the female of Ev. hashiguchii because the spermathecae of this species is very different from that of Ev. orcyi. Furthermore, the similarity of both sexes of Ev. orcyi with other species like Ev. carmelinoi, Ev. evandroi and Ev. lenti, and the fact that all these species were found sympatrically in the sampled area, reinforce the validity of Ev. orcyi for both sexes.

\section{Conclusion}

With the description of Evandromyia orcyi sp. nov., six species of the subgenus Aldamyia have been reported in the State of Mato Grosso do Sul.

\section{Competing interests}

The authors declare that they have no competing interests.

\section{Authors' contributions}

AGO, PSA, CCS and JDAF participated in the morphological analysis of the specimens and taxonomic discussion. AGO and PSA collected the material in the field. CCS and JDAF did the drawings and measurements of the new species. AGO, PSA, CCS and JDAF drafted the manuscript. All the authors read and agreed with this manuscript.

\section{Acknowledgements}

We thank the staff of the "Laboratório Regional de Entomologia de Três Lagoas", Airton Marques de Miranda and Marcos Antonio Batista Teixeira for 
the support in the collection of phlebotomines. The Coordinator of Health Surveillance, Jeane Alves de Jesus and the Coordinator of Vector Control, Reginaldo de Oliveira Souza for the logistical support in the municipality of Selvíria. JDAF is research fellow supported by the National Council for the Development of Research of Brazil (CNPq).

\section{Author details}

${ }^{1}$ Laboratório de Parasitologia Humana, Centro de Ciências Biológicas e da Saúde, Universidade Federal de Mato Grosso do Sul, Cidade Universitária s/n, 79070-900 Campo Grande, MS, Brazil. Grupo de Estudos em Leishmanioses, Coleção de Flebotomíneos, Centro de Referência Nacional e Internacional para Flebotomíneos, Instituto René Rachou, Fiocruz, Av. Augusto de Lima 1715, 30190-002 Belo Horizonte, MG, Brazil. ${ }^{3}$ Laboratório Regional de Entomologia, Núcleo Regional de Saúde, Secretaria de Estado de Saúde, Rua Hilda Bergo Duarte, 940, 79806-020 Dourados, MS, Brazil.

Received: 2 December 2014 Accepted: 8 April 2015 Published online: 17 April 2015

\section{References}

1. Andrade AJ, Shimabukuro PHF, Galati EAB. On the taxonomic status of Phlebotomus breviductus Barretto, 1950 (Diptera: Psychodidae: Phlebotominae). Zootaxa. 2014;3734:477-84.

2. Ladeia-Andrade S, Fe NF, Sanguinette CC, Andrade Filho JD. Description of Trichophoromyia uniniensis, a new phlebotomine species (Diptera: Psychodidae: Phlebotominae) of Amazonas State, Brazil. Paras Vectors. 2014;7:400.

3. Sábio PB, Andrade AJ, Galati EAB. Assessment of the taxonomic status of some species included in the Shannoni complex, with the description of a new species of Psathyromyia (Diptera: Psychodidae: Phlebotominae). J Med Entomol. 2014;51:331-41.

4. Machado TO, Bragança MAL, Carvalho LC, Andrade Filho JD. Species diversity of sand flies (Diptera: Psychodidae) during different seasons and in different environments in the district of Taquaruçú, State of Tocantins, Brazil. Mem Inst Oswaldo Cruz. 2012;107:955-9.

5. Carvalho GML, Brazil RP, Ramos MCNF, Meira PCLS, Zenóbio APLA, Botelho HA, et al. Ecological aspects of phlebotomine sandflies (Diptera: Psychodidae) from a cave of the Speleological Province of Bambuí. Brazil PLos ONE. 2013;8:e77158.

6. Galati EAB: Morfologia e Taxonomia. Classificação de Phlebotominae. In Flebotomíneos do Brasil. Edited by Rangel RF, Lainson R. Rio de Janeiro: Fiocruz; 2003: 23-206.

7. Almeida OS, Leite JA, Batista PM, Touro RBS, Araújo VS, Souza EJ, et al. Fauna of phlebotomine sand flies (Diptera, Psychodidae) in areas with endemic American cutaneous leishmaniasis in the State of Mato Grosso do Sul, Brazil. Rev Bras Entomol. 2013;57:105-12

8. Figueira EAG, Silva G, Chagas ECS, Shimabukuro PHF. Phlebotomine sandflies (Diptera: Psychodidae) from Lábrea, state of Amazonas, Brazil, with a description of Evandromyia (Aldamyia) apurinan Shimabukuro, Figueira \& Silva, sp. nov. Mem Inst Oswaldo Cruz. 2013;108:208-87.

9. Mangabeira Filho O. Sobre duas novas especies de Flebotomus (Diptera: Psychodidae). Mem Inst Oswaldo Cruz. 1938;33:349-56.

10. Ryan L, Fraiha H, Lainson R, Shaw JJ. New phlebotomine sandflies of the walkeri group (Diptera: Psychodidae) from Pará State, Brazil, with a pictorial key 1. Mem Inst Oswaldo Cruz. 1986;81:323-31.

11. Martins AV, Falcão AL, Silva JE. Nota sôbre os flebótomos do Estado de Goiás, com a descrição duas espécies novas e da fêmea de Lutzomyia longipennis (Barretto, 1946) e a redescrição do macho da L. evandroi (Costa Lima e Antunes, 1936) (Diptera: Psychodidac). Rev Bras Malarial Doença Trop. 1962;14:379-99.

12. Leon $R$, Teran R, Neira M, Le Pont F. Ecuadorian sand-flies: two new species of the genus Evandromyia (Diptera, Psychodidae). Bullet Soc Entomol Fr. 2009;114:143-8.

\section{Submit your next manuscript to BioMed Central and take full advantage of:}

- Convenient online submission

- Thorough peer review

- No space constraints or color figure charges

- Immediate publication on acceptance

- Inclusion in PubMed, CAS, Scopus and Google Scholar

- Research which is freely available for redistribution 